\title{
Preface
}

\section{Caring for Sepsis Patients: An Update}

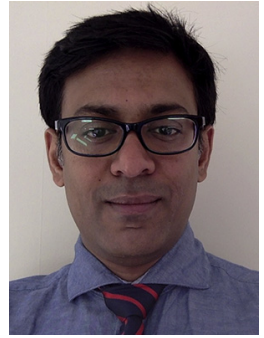

Manu Shankar-Hari, MSc, MD, $\mathrm{PhD}, \mathrm{MB}$ BS, FRCA, FFICM

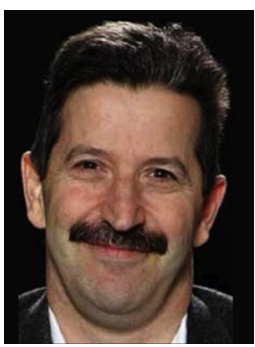

Mervyn Singer, MB BS, MD, $F R C P($ Lon), FRCP(Edin), FFICM

Editors

Sepsis is a common illness and is recognized in the recent World Health Organization resolution as a global health priority. ${ }^{1}$ In February 2016, the definitions of sepsis were updated with the emphasis on organ dysfunction being triggered by a dysregulated host response to infection. Septic shock was redefined as a subset of sepsis carrying a worse prognosis. Explicit clinical criteria were published for identifying sepsis, septic shock, and infected patients at risk of bad outcomes. ${ }^{2-4}$

The new sepsis definitions emphasized reliability, feasibility, and validity attributes, and these have been generally confirmed in recently published epidemiology studies. Despite issues surrounding coding, the incidence of sepsis is increasing due to an aging population and increasing medical interventions. Many patients who survive their sepsis-related hospitalization continue to suffer from longer-term morbidity and increased risk of death. ${ }^{5-10}$

Despite the significant advances in our understanding of the pathobiology of sepsis, sepsis management remains largely supportive, with no specific treatments shown to be of benefit. Tailoring treatments based on biological (clinical and laboratory) patient characteristics will likely add further benefit over and above that achieved through improving the general quality of care as recommended by the Surviving Sepsis Campaign guidelines. Furthermore, a number of novel treatments are in the pipeline. To achieve this goal, our focus is now on both identifying septic patients most likely to benefit from specific interventions or who are at greatest risk of bad outcomes and exploring novel trial designs to identify specific treatments in identified subpopulations. ${ }^{11-14}$ 
This issue of Critical Care Clinics is dedicated to providing a comprehensive update to practicing physicians on the epidemiology and biology of sepsis, ongoing controversies, clinical care, and novel treatment strategies.

\author{
Manu Shankar-Hari, MSc, MD, PhD, MB BS, FRCA, FFICM \\ Department of Critical Care Medicine \\ ICU Offices \\ Guy's and St Thomas' Hospital \\ NHS Foundation Trust \\ London SE1 7EH, United Kingdom
}

Mervyn Singer, MB BS, MD, FRCP(Lon), FRCP(Edin), FFICM

Intensive Care Medicine

University College London

Cruciform Building, Gower Street London WC1E 6BT, United Kingdom

E-mail addresses:

manu.shankar-hari@kcl.ac.uk (M. Shankar-Hari)

m.singer@ucl.ac.uk (M. Singer)

\title{
REFERENCES
}

1. Reinhart K, Daniels R, Kissoon N, et al. Recognizing sepsis as a global health priority - a WHO resolution. N Engl J Med 2017;377(5):414-7.

2. Singer M, Deutschman CS, Seymour CW, et al. The Third International Consensus Definitions for Sepsis and Septic Shock (Sepsis-3). JAMA 2016;315(8):801-10.

3. Seymour CW, Liu VX, Iwashyna TJ, et al. Assessment of clinical criteria for sepsis: for the Third International Consensus Definitions for Sepsis and Septic Shock (Sepsis-3). JAMA 2016;315(8):762-74.

4. Shankar-Hari M, Phillips GS, Levy ML, et al. Developing a new definition and assessing new clinical criteria for septic shock: for the Third International Consensus Definitions for Sepsis and Septic Shock (Sepsis-3). JAMA 2016; 315(8):775-87.

5. Raith EP, Udy AA, Bailey M, et al. Prognostic accuracy of the SOFA score, SIRS criteria, and qSOFA score for in-hospital mortality among adults with suspected infection admitted to the intensive care unit. JAMA 2017;317(3):290-300.

6. Russell JA, Lee T, Singer J, et al. The Septic Shock 3.0 definition and trials: a vasopressin and septic shock trial experience. Crit Care Med 2017;45(6):940-8.

7. Freund $Y$, Lemachatti N, Krastinova E, et al. Prognostic accuracy of Sepsis-3 criteria for in-hospital mortality among patients with suspected infection presenting to the emergency department. JAMA 2017;317(3):301-8.

8. Shankar-Hari M, Ambler M, Mahalingasivam V, et al. Evidence for a causal link between sepsis and long-term mortality: a systematic review of epidemiologic studies. Crit Care 2016;20(1):101.

9. Prescott HC, Osterholzer JJ, Langa KM, et al. Late mortality after sepsis: propensity matched cohort study. BMJ 2016;353:i2375.

10. Prescott HC, Langa KM, Iwashyna TJ. Readmission diagnoses after hospitalization for severe sepsis and other acute medical conditions. JAMA 2015;313(10): 1055-7. 
11. Rhodes A, Evans LE, Alhazzani W, et al. Surviving Sepsis Campaign: International Guidelines for Management of Sepsis and Septic Shock: 2016. Intensive Care Med 2017;43(3):304-77.

12. Hotchkiss RS, Sherwood ER. Immunology. Getting sepsis therapy right. Science 2015;347(6227):1201-2.

13. Prescott HC, Calfee CS, Thompson BT, et al. Toward smarter lumping and smarter splitting: rethinking strategies for sepsis and acute respiratory distress syndrome clinical trial design. Am J Respir Crit Care Med 2016;194(2):147-55.

14. Shankar-Hari M, Rubenfeld GD. The use of enrichment to reduce statistically indeterminate or negative trials in critical care. Anaesthesia 2017;72(5):560-5. 